\title{
THE INFLUENCE OF NODAL ROOTS ON THE GROWTH AND BRANCHING OF WHITE CLOVER (TRIFOLIUM REPENS L.)
}

\author{
S.M. SOLANGAARACHCHI \\ Unit of Plant Population Biology, School of Biological Sciences, University \\ College of North Wales, Bangor, Gwynedd, LL57 2UW, U.K.
}

(Received: 23 May 1995; accepted: 01 December 1995)

\begin{abstract}
White clover (Trifolium repens) is a stoloniferous legume, introduced into temperate pastures to improve the quality of fodder. It bears adventitious roots at each node. The effect of preventing nodal root formation in various ranks of stolons (main, primary, and main + primary) on growth and branching was studied. Reduced growth and branching were observed following prevention of nodal root formation. Reduction was predominantly due to the treatments for prevention of root formation on the main stolon. The least reduction in growth was found due to the prevention of root formation on primary stolons.
\end{abstract}

Key words : Nodal roots, Trifolium repens, white clover.

\section{INTRODUCTION}

Trifolium repens $\mathrm{L}$. (white clover) is an agronomically important stoloniferous perennial legume, that has been introduced into pastures in many temperate countries. Its growth is monopodial, and each node bears a leaf, an axillary bud (which develops into a branch) and an adventitious root. Growth and branching are the major means by which it increases the number of leaves and number of sites of adventitious roots, though the recruitment of seedlings also plays a significant role in maintaining genetic diversity within the $T$. repens population. ${ }^{1}$ Roots are the sole connection between plant shoot and soil from which nutrients and water are absorbed. ${ }^{2-4}$ The tap root is well developed whilst the adventitious roots (nodal roots) are smaller and shallower. ${ }^{5}$ Root characters such as number of fibrous roots, root dry weight, tap root base width, length to first primary lateral and number of nodal roots differ between varieties. ${ }^{6}$ Initially the adventitious roots are very thin, but later they increase in size and develop lateral branches and resemble tap roots, which is important when new clones are established from fragments of the parental clone. ${ }^{7}$ Nodal roots affect the persistence of plants. The winter survival of white clover is superior to that of Ladino clover, ${ }^{8}$ and this is due to a higher proportion of adventitious roots. $\mathrm{Cook}^{9}$ also has pointed out that the death risk to the genet is lessened when there are nodal roots. Thus, rooted parts of a genet may grow independently after the main shoot or tap root is damaged. Nodal roots which are being continually added to the clone, exploit new soil volumes more quickly and closer to the place at which nutrients and water are used than may growth from a tap root system.

* Present address: Department of Botany, University of Kelaniya, Kelaniya, Sri Lanka. 
The performance of an individual white clover plant is inevitably determined by the degree of stolon branching and further development of the shoot. There may be a relationship between the root of each node and the growth of the leaf and associated axillary bud, attached to the same node. It has been suggested that the number of stolon tips (or frequency of branching) is positively correlated with the growth of roots and the frequency of nodal roots. ${ }^{5,10}$ This information leads one to argue that the development of a stolon bud to form a branch may be at least partially dependent on the presence of a root at the node, and the occurrence of a rooted node at a branch may influence the growth and survival of that branch. Chapman ${ }^{10}$ has shown that the elongation rate and the node appearance rate on rooted branches were approximately similar to those on the parental stolon, whilst that of unrooted branches was lower. Thus the survival is greater in branches from rooted nodes, as adventitious roots make the branches independent of the parent plant.

This paper describes an experiment designed to study the effects of nodal roots on growth and branching of $T$. repens. Root development normally occurs only if a node is firmly anchored to the substrate. So if the stolons are raised from the substrate, root development can be prevented. The results of this study would be useful to interpret the growth of clover in different environments, such as in association with different species of grasses.

\section{METHODS AND MATERIALS}

Three clones of $T$. repens were selected from a collection made by Trathan ${ }^{11}$ in a permanent pasture in North Wales (Clone A -short internodes, short petioles, relatively small leaves, more horizontally placed petioles and with thin stolons. Clone B - intermediate in internodal length, longer petioles, relatively large leaves, more vertically held petioles, thicker stolons. Clone C - Longer internodes, longer petioles, large leaves, more horizontally placed petioles, intermediate thickness of stolons).

Uniform (in size and age) single node cuttings were taken from single clones of each type and planted in compartmented trays, filled with Jhon Innes No 1 compost. These were kept in a heated glasshouse. After 14 days of growth (when the plants formed five to six leaves), uniform plants were selected and transplanted into trays $(22 \times 35 \times 5 \mathrm{~cm})$ filled with the same compost. Each plant was transplanted at one end of tray, aligned to grow towards the other end. Seven days after establishment three replicates from each clone were given the following treatments beyond the third node on the main stolon:

Treatment 1 - control (no treatment).

Treatment 2 - root formation was prevented on the primary branches (branches arising from the main stolon). 
Treatment 3 - root formation was prevented on the main stolon.

Treatment 4 - Root formation was prevented on the main stolon and its primary branches.

The formation of roots was prevented by placing pieces of very fine plastic mesh between the soil surface and stolon nodes. The plants were watered normally and arranged in a completely randomised design and rerandomised weekly. After six weeks of growth, plants were harvested as follows:

Each plant was divided into two parts (distal - treated, and proximal - untreated) at the fifth node on the main stolon. On the distal parts of the plants (treated parts) the following measurements were made: the number of nodes, the length and dry weight of stolons on the main, primary and secondary stolons (branches arising from the primary stolons) and total number of branched nodes. The total number of nodes, the total length of stolons and percentage of nodes forming branches were also estimated. The dry weights of shoots and roots were also measured after oven drying at $70^{\circ} \mathrm{C}$ until a constant weight. was obtained. The shoots and roots in the proximal part (untreated part) were separated and dry weights were measured.

\section{RESULTS}

Comparison of the distal (treated) parts : Tables 1a \& b show all the parameters measured and estimated. Prevention of root formation has affected the growth of clover significantly $(\mathrm{p}<0.05)$. The prevention of rooting on primary stolons however did not show significant difference from the control, except for the length and dry weights of secondary stolons. Prevention of rooting on main and main + primary stolons reduced the number of nodes significantly $(p<0.05)$ by $10 \%, 42 \%, 73 \%$ and $59 \%$ on the main, primary, secondary and total stolons respectively. The length and the dry weight of stolons also showed similar results. The number of branched nodes was not significantly reduced in treatment 2 , but it was significantly reduced by 55\% in treatments 3 and 4 compared to the control. However, the average percentage of branching was not significantly different from the control, and the values were $39 \%, 38 \%, 43 \%$ and $41 \%$ for control, treatments 2,3 , and 4 respectively. Clonal differences were also significant $(p<0.05)$ The number of nodes, number of branched nodes, length and dry weight of stolons were highest in Clone B and they were the lowest in Clone $\mathrm{C}$, whilst Clone A had intermediate values. The percentage of branching was similar in all clones and they were $41 \%, 39 \%$ and $41 \%$ in clones A, B and C respectively.

Comparison of the proximal (untreated) parts: Tables $2 \mathrm{a} \& \mathrm{~b}$ show the dry weights of shoots and roots of the distal (treated) and proximal (untreated) parts. There was a gradual increase in dry weights of the shoot and roots of the proximal 
part of the plant and a gradual decrease in the distal part with increasing the amount of prevention of the formation of nodal roots. Prevention of root formation on main and primary stolons (treatment 4) on the distal part decreased the dry weight of shoot by $48 \%$ significantly $(\mathrm{p}<0.05)$ of the control, whilst it increased the dry weight of the proximal part by $49 \%$ significantly $(p<0.05)$ of the control. Similarly, the dry weight of roots of the distal and proximal parts decreased and increased respectively. There were significant differences between clones too (Table $2 \mathrm{~b}$ ), and the trend was similar to that of other variables described in Table $1 \mathrm{~b}$.

Table 1a: Comparison of the effect of preventing root formation on the growth and branching of three different clones (A, B \& C) of white clover (Trifolium repens).

Variable

Treatment

(stolons in which rooting was prevented) 1 2 $3 \quad 4$ Control Primary Main Primary+Main

Number of nodes on:

$\begin{array}{lcccc}\text { Main stolon } & 23.00^{\mathrm{a}} & 22.33^{\mathrm{a}} & 20.67^{\mathrm{b}} & 20.67^{\mathrm{b}} \\ \text { Primary stolons } & 182.3^{\mathrm{a}} & 176.3^{\mathrm{a}} & 98.10^{\mathrm{b}} & 112.4^{\mathrm{b}} \\ \text { Secondary stolons } & 277.0^{\mathrm{a}} & 221.6^{\mathrm{a}} & 79.7^{\mathrm{b}} & 68.8^{\mathrm{b}} \\ \text { Total stolons } & 482.3^{\mathrm{a}} & 420.2^{\mathrm{a}} & 198.4^{\mathrm{b}} & 201.9^{\mathrm{b}}\end{array}$

Length (cm) of:

$\begin{array}{lrrrr}\text { Main stolon } & 30.9^{\mathrm{a}} & 28.8^{\mathrm{a}} & 23.6^{\mathrm{b}} & 22.4^{\mathrm{b}} \\ \text { Primary stolons } & 193.3^{\mathrm{a}} & 182.1^{\mathrm{a}} & 85.1^{\mathrm{b}} & 113.0^{\mathrm{b}} \\ \text { Secondary stolons } & 198.2^{\mathrm{a}} & 132.9^{\mathrm{b}} & 35.0^{\mathrm{c}} & 37.1^{\mathrm{c}} \\ \text { Total stolons } & 422.0^{\mathrm{a}} & 344.0^{\mathrm{a}} & 144.0^{\mathrm{b}} & 113.0^{\mathrm{b}}\end{array}$

Dry weight (g) of:

Main stolon

$0.195^{\mathrm{a}}$

$0.198^{\mathrm{a}}$

$0.117^{\mathrm{b}}$

$0.153^{b}$

Primary stolons

$0.950^{\mathrm{a}}$

$0.886^{\mathrm{a}}$

$0.379^{b}$

$0.617^{c}$

Secondary stolons

$0.823^{a}$

$0.534^{b}$

$0.153^{\mathrm{c}}$

$0.157^{\mathrm{c}}$

Total stolons

$1.968^{\mathrm{a}}$

$1.618^{\mathrm{a}}$

$0.649^{\mathrm{b}}$

$0.927^{\mathrm{b}}$

Number of branched nodes

$183.8^{\mathrm{a}}$

$175.7^{\mathrm{a}}$

$83.7^{\mathrm{b}}$

$82.4^{\mathrm{b}}$

The values are the overall means of all three clones (A, B \& C). Means were compared with Tukey's HSD value. Values sharing the same superscript within each row do not differ significantly $(p<0.05)$. 
Table 1b: Comparison of three clones (A, B \& C) of white clover (Trifolium repens).

\begin{tabular}{lccc}
\hline Variable & \multicolumn{2}{c}{ Clone } \\
& $\mathrm{A}$ & $\mathrm{B}$ & $\mathrm{C}$ \\
\hline Number of nodes on: & & & \\
Main stolon & $23.17^{\mathrm{a}}$ & $24.42^{\mathrm{b}}$ & $17.42^{\mathrm{c}}$ \\
Primary stolons & $159.6^{\mathrm{a}}$ & $185.1^{\mathrm{b}}$ & $82.3^{\mathrm{c}}$ \\
Secondary stolons & $171.8^{\mathrm{a}}$ & $232.2^{\mathrm{b}}$ & $81.3^{\mathrm{c}}$ \\
Total stolons & $354.6^{\mathrm{a}}$ & $441.7^{\mathrm{b}}$ & $180.9^{\mathrm{c}}$ \\
& & & \\
Length (cm) of: & & & \\
Main stolon & $25.58^{\mathrm{a}}$ & $28.75^{\mathrm{b}}$ & $24.92^{\mathrm{a}}$ \\
Primary stolons & $141.3^{\mathrm{a}}$ & $190.7^{\mathrm{b}}$ & $98.3^{\mathrm{c}}$ \\
Secondary stolons & $87.8^{\mathrm{a}}$ & $154.3^{\mathrm{b}}$ & $60.4^{\mathrm{a}}$ \\
Total stolons & $255.0^{\mathrm{a}}$ & $374.0^{\mathrm{c}}$ & $184.0^{\mathrm{b}}$ \\
& & & \\
Dry weight (g) of: & & & $0.143^{\mathrm{a}}$ \\
Main stolon & $0.156^{\mathrm{a}}$ & $0.198^{\mathrm{b}}$ & $0.436^{\mathrm{c}}$ \\
Primary stolons & $0.709^{\mathrm{a}}$ & $0.979^{\mathrm{b}}$ & $0.216^{\mathrm{c}}$ \\
Secondary stolons & $0.413^{\mathrm{a}}$ & $0.621^{\mathrm{b}}$ & $0.795^{\mathrm{c}}$ \\
Total stolons & $1.278^{\mathrm{a}}$ & $1.798^{\mathrm{b}}$ & \\
Number of branched & & & $68.8^{\mathrm{c}}$ \\
nodes & $137.1^{\mathrm{a}}$ & $188.3^{\mathrm{b}}$ & \\
\hline
\end{tabular}

The values are the overall means of all treatments for each clone (distal part, i.e. treated part). Means were compared with Tukey's HSD value. Values sharing the same superscript within each row do not differ significantly $(\mathrm{p}<0.05)$.

Table 2a: Comparison of the overall means of the dry weights of white clover when root formation was prevented on various ranks of stolons.

\begin{tabular}{|c|c|c|c|c|}
\hline \multirow[t]{2}{*}{ Variable } & \multicolumn{4}{|c|}{$\begin{array}{c}\text { Treatment } \\
\text { (stolons in which rooting was prevented) }\end{array}$} \\
\hline & $\begin{array}{c}1 \\
\text { Control }\end{array}$ & $\begin{array}{c}2 \\
\text { Primary }\end{array}$ & $\begin{array}{c}3 \\
\text { Main }\end{array}$ & $\begin{array}{c}4 \\
\text { Main+Primary }\end{array}$ \\
\hline \multicolumn{5}{|l|}{ Shoot dry weight (g): } \\
\hline Distal (treated) & $3.588^{\mathrm{a}}$ & $3.223^{\mathrm{a}}$ & $1.218^{\mathrm{b}}$ & $1.870^{c}$ \\
\hline Proximal (untreated) & $6.43^{\mathrm{ac}}$ & $5.84^{\mathrm{a}}$ & $7.33^{\mathrm{c}}$ & $9.61^{b}$ \\
\hline \multicolumn{5}{|l|}{ Root dry weight (g): } \\
\hline Distal (treated) & $1.235^{\mathrm{a}}$ & $0.713^{\mathrm{b}}$ & $0.189^{c}$ & -- \\
\hline Proximal (untreated) & $1.882^{\mathrm{ab}}$ & $1.448^{\mathrm{a}}$ & $1.987^{b}$ & $2.151^{\mathrm{b}}$ \\
\hline
\end{tabular}

The values are overall means for clones A, B and C. Means sharing the same superscript within each row do not differ significantly $(\mathrm{p}<0.05)$. Means were compared with Tukey's HSD values. 
Table 2b: Comparison of the dry weights of proximal (untreated) and distal (treated) parts of shoots and roots of different clones (A, B \& C) of white clover.

Variable

Clones

A

B

C

Shoot dry weight (g):

Distal (treated)

$2.476^{\mathrm{a}}$

$3.471^{b}$

$1.477^{\circ}$

Proximal (untreated)

$6.99^{\mathrm{a}}$

$9.97^{\mathrm{b}}$

$4.95^{\mathrm{c}}$

Root dry weight:

Distal (treated)

$0.718^{a c}$

$0.948^{\mathrm{a}}$

$0.471^{\mathrm{c}}$

Proximal (untreated)

$1.542^{\mathrm{a}}$

$2.726^{b}$

$1.334^{\mathrm{a}}$

Means (overall means of all treatments) sharing the same superscript within each row do not differ significantly $(p<0.05)$. Means were compared with Tukey's HSD values.

\section{DISCUSSION}

The importance of nodal roots for the growth of branches of $T$. repens was clearly observed in this study. When roots were prevented from forming on a part of a clover plant, the number of nodes, the length, dry weight of stolons and number of branched nodes were all reduced on that part. However, the percentage of buds forming branches was not affected. Whether or not a bud grows out to form a branch is apparently unaffected by the presence of a root at that node. Reduced growth and branching due to the damage of roots have also been reported for other clonally spreading species, e.g. the aquatic fern Salvinia molesta. ${ }^{12}$ Newly formed ramets are normally dependent on the parental parts and in time they become independent and supply their own requirements. When a bud starts to develop, its further growth is strongly supported by the root at its parental node and the further growth of branches is related to the local environment or the efficiency of each nodal root in absorbing nutrients and water. Similar independence of nodules in other stolonoferous species such as Ranunculus repens $\mathrm{L}$. and Carex arenaria L. has been observed by Ginzo \& Lovell ${ }^{13,14}$ and Noble ${ }^{15}$ respectively.

In the experimental treatments, where the root formation of consecutive nodes was prevented, the effect was detected not only at the same node, but also at subsequent nodes. This is because the newly forming branches in their initial development are dependent on the parental parts, presumably, through an acropetal movement of nutrients and assimilates. Thus if a module is supplied with poor resources (e.g. due to absence of roots) then the chance of supporting the subsequent modules is further reduced. As more new nodes form, this leads 
to a cumulative disadvantage and both further growth and branching decline. Davies and Evans ${ }^{16}$ also have shown that the development of axillary buds in $T$. repens is reduced by defoliation and by stolon shading.

Prevention of the formation of roots on primary stolons did not affect their own growth. It was the absence of roots on the main stolon that primarily affected the growth of its primary stolons. These results indicate the major role of the main stolon roots in supporting its own branches. The present results agree with the field observations made by Chapman ${ }^{10}$ who showed that the occurrence of both a root and a branch at a node in $T$. repens is highly correlated.

A very interesting result of this study is the marked effect of treatments on the extending (distal) part of a plant, on the growth of the untreated (proximal) part. When root formation was prevented in treated part of the plant, the root and shoot growth in the untreated part were greater than that in the control plants. In the deradicated parts of the plant, growth and branching have been reduced and the more roots were prevented from forming, the less growth was made. The consequence was a shift in the vigour of growth to the proximal (untreated) part of the plant. Perhaps this suggests that the presence of roots on a stolon allows it to compete with other parts of the plant, for other limiting resources. e.g. assimilates. When rooting is prevented on some parts, the rest gains freer access to these resources. Such integration between the parts of a single clone has also been shown by Harnett \& Bazzaz. ${ }^{17}$ Clonal integration may thus enhance the survival and hence fitness of the genet, in an environment that is patchy in resources and hazards:

The results are useful in understanding the situation in the field. Due to its growth habit, white clover stolons are continually moving through grasses in pastures. The density of tillers which varies depending on the species in an established sward determines the light regime within the sward, ${ }^{18,19}$ the degree of physical interference, the amount of bare ground in which clover can root and the gaps in which it may branch freely, e.g. Lolium perenne Lam. and Cynosurus cristatus create more loosely structured swards than Holcus lanatus and Agrostis tenuis. ${ }^{18}$ Under dense tillers of grass canopy, clover is at a disadvantage in nodal root formation, which plays a major role in the performance of clover.

Therefore, the results suggest that in order to improve the quality of fodder, the management methods should attempt to minimize the effect of physical interference to clover, by selecting proper grass species in pastures within which the frequency of rooting of $T$. repens is higher, and also by selecting proper clover clones which root frequently, so that clover can perform well within pastures. Furthermore, if our aim is to obtain maximum sustainable yield, the above aspects could be considered in agriculture, where mixed species are grown. 


\section{Acknowledgement}

I thank Prof. J.L. Harper, for guidance and advice and the Association of Commonwealth Universities and British Council for financial support.

\section{References}

1. Chapman D.F. (1987). Natural reseeding and Trifolium repens demography in grazed hill pastures. II. Seedling appearance and survival. Journal of Applied Ecology 24: 1037-1043.

2. Andrews R.E. \& Solanki S.S. (1966). A comparative root morphology for inbred lines of corn as related to performance. Agronomy Journal 58:415-418.

3. Andrews R.E. \& Newman E.I. (1970). Root density and competition for nutrients. Oecologia Plantarum 5: 319-334.

4. Nye P.H. \& Tinker P.B. (1977). Solute movement in the soil-root system. Studies in Ecology 4. Blackwell Scientific, Oxford.

5. Haycock R. (1982). A comparison of dry matter partitioning in seminal and adventitious plants of Trifolium repens. Annals of Botany 50: 161-166.

6. Caradus J.R. (1977). Structural variation of white clover root system. New Zealand Journal of Agricultural Research 20: 213-219.

7. Erith A.G. (1924). White clover (Trifolium repens L.): a monograph. Duckworth, London.

8. Ronningen T.S. (1953). Susceptibility to winter injury and some other characteristics in Ladino and White clover. Agronomy Journal 45: 114-117.

9. Cook R. (1979). Asexual reproduction: a future consideration. American Naturalist 113: 769-7.72.

10. Chapman D.F. (1983). Growth and demography of Trifolium repens stolons in grazed pastures. Journal of Applied Ecology 20: 597-608.

11. Trathan P. (1983). Clonal interactions of Trifolium repens and Lolium perenne. Ph.D. thesis. University of Wales.

12. Solangaarachchi S.M. \& Dushyantha R.P.K. (1994). Growth and branching of damaged Salvinia molesta. Journal of the National Science Council of Sri Lanka 22(3): 271-278. 
13. Ginzo H.D. \& Lovell P.H. (1973). Aspects of the comparative physiology of Ranunculus bulbosus L. and $R$. repens L.. I. Response to nitrogen. Annals of Botany 37: 753-764.

14. Ginzo H.D. \& Lovell P.H. (1973). Aspects of the comparative physiology of Ranunculus bulbosus L. and $R$. repens L.. II. Carbon dioxide assimilation and distribution of photosynthates. Annals of Botany 37: 765-776.

15. Noble J.C. (1976). The population biology of rhizomatous plants. Ph.D. thesis. University of Wales.

16. Davies A. \& Evans M.E. (1990). Axillary bud development in white clover in relation to defoliation and shading treatments. Annals of Botany 66: 349-357.

17. Hartnett D.C. \& Bazzaz F.A. (1983). Physiological integration among intraclonal ramets in Solidago canadensis L. Ecology 64: 779-788.

18. Solangaarachchi S.M. (1985). The nature and control of white clover (Trifolium repens L.). Ph.D. thesis. University of Wales.

19. Thompson L. \& Harper J.L. (1988). The effect of grasses on the quality of transmitted radiation and its influence on the growth of White Clover (Trifolium repens). Oeologia (Berlin) 75: 343-347. 